\title{
Respon Dosen dan Mahasiswa Terhadap Penggunaan Media Pembelajaran Multimedia Interaktif Macromedia Flash
}

\author{
Dewi Hikmah Marisda*, Rahmawati, Andi Arie Andriani \\ Program Studi Pendidikan Fisika, Universitas Muhammadiyah Makassar \\ *Email: dewihikmah@unismuh.ac.id
}

Received: 14 November 2019;

Accepted: 5 Maret 2020;

Published: 16 Maret 2020

DOI: http://dx.doi.org/10.29303/jpft.v6i1.1463

\begin{abstract}
This research is motivated by changes in the science learning process, especially at the tertiary level which trains student teacher candidates to use their thinking potential through social interaction in learning. In addition, the lack of development of the media in Integrated Science lectures is also a particular concern in this study. The purpose of this study is to analyze how the response of lectures and students of Physics Education at the University of Muhammadiyah Makassar to the use of Interactive Multimedia Macromedia Flash in Integrated Science lectures. The research sample consisted of 5 (five) integrated science lectures and 35 (thirty-five) students. This research is qualitative research that describes how the response of lecturers and students to the learning media used. The data in this research are lecturer response questionnaire data and student response questionnaire data. The data is then analyzed descriptively. Based on the results of the validation analysis of learning media by the validator (expert), the Aiken index average 0,76 in the medium category. Based on the results of the study found $87,50 \%$ of lecturers responded positively to the use of interactive multimedia learning media with Macromedia Flash in Integrated Science lecturers. And as much as 83,86 \% students gave a positive response to the use of interactive multimedia learning media with Macromedia flash in Integrated Science lectures.
\end{abstract}

Keywords: Integrated Science; Interactive Multimedia; Lecturer Response; Student Response

\section{PENDAHULUAN}

Perubahan proses pembelajaran IPA, khususnya pada tingkatan perguruan tinggi perlu diarahkan pada upaya melatih mahasiswa calon guru menggunakan potensi berpikir yang dimilikinya melalui interaksi sosial dalam pembelajaran. Namun, dalam prosesnya, ditemukan sejumlah permasalahan yakni para pendidik kurang begitu mengenal model pembelajaran yang mampu mengembangkan kemampuan berpikir (Dewi \& Haryanto, 2019).

Mata kuliah IPA Terpadu merupakan salah satu mata kuliah inti prodi yang sangat penting untuk dibekalkan pada mahasiswa calon guru. Adapun konten materi dari IPA Terpadu merupakan keterkaitan antara disiplin ilmu Fisika, Kimia, dan Biologi. Aspek penting dari mata kuliah IPA Terpadu ini adalah bagaimana meramu materi dari masing-masing disiplin ilmu menjadi satu kesatuan utuh yang nantinya akan membentuk kajian tersendiri yaitu IPA Terpadu. Untuk dapat membelajarkan mahasiswa pada perkuliahan IPA Terpadu yang sifatnya abstrak dan kompleks pada beberapa materi, dibutuhkan model pembelajaran yang efektif dalam meminimalisir miskonsepsi (kesalahpahaman), juga meningkatkan keterampilan berpikir kritis mahasiswa. Salah satu indikator terjadinya miskonsepsi adalah jawaban yang diberikan peserta didik benar akan tetapi peserta didik tidak mampu menjelaskan alasan yang tepat dalam menjawab dan disertai keyakinan yang tinggi akan kebenaran jawaban yang disampaikan (Haeroni et al. 2019).

Penerapan model pembelajaran saja dalam perkuliahan IPA Terpadu masih 
dirasa kurang oleh dosen untuk mengurangi miskonsepsi yang sering terjadi pada mahasiswa. Untuk itu, diperlukan pula penggunaan media pembelajaran dalam proses perkuliahan. Media pembelajaran mempunyai peranan yang sangat penting dalam menunjang keberhasilan proses pembelajaran. Dengan adanya media pembelajaran akan menambah semangat dan pemahaman siswa terhadap materi yang diajarkan (Hariyati, 2014). Sejalan dengan itu dikatakan pula bahwa media pembelajaran memiliki beberapa manfaat yaitu menyamakan persepsi siswa, mengkonkritkan konsep-konsep yang abstrak, menampilkan objek yang terlalu besar atau kecil, dan memperlihatkan gerakan yang terlalu cepat atau lambat. Sejalan dengan itu Pratiwi, et al. (2019) dalam jurnalnya mengatakan manfaat penggunaan medi pembelajaran yaitu: penyajian lebih baku, menarik, interaktif, dan efisien.

Perkembangan teknologi membawa perubahan dalam penggunaan media. Perkembangan teknologi komputer menghadirkan inovasi dalam proses pembelajaran sains di era teknologi informasi ini adalah berbasis multimedia. Perkembangan teknologi computer menghadirkan inovasi dalam proses pembelajaran sains (Rahmawati, 2019). Salah satu media pembelajaran yang merespon perkembangan teknologi yaitu multimedia interaktif (Dewi \& Haryanto, 2019). Multimedia interaktif merupakan salah satu pengaplikasian teknologi dalam pembelajaran (Hadijah, 2018).

Beberapa penelitian menunjukkan proses pembelajaran yang menggunakan multimedia interaktif memberikan hasil belajar yang lebih baik. Seperti penelitian yang dilakukan oleh Leow \& Neo (2014) di Malaysia, terdapat peningkatan yang signifikan pada tes hasil belajar dan menunjukkan perubahan sikap positif peserta didik, menjadi lebih aktif dan termotivasi dalam proses pembelajaran (Leow \& Neo, 2014). Demikian pula penelitian yang dilakukan oleh Muthulaksmi, dari hasil penelitian beliau, menunjukkan bahwa ada perbedaan yang signifikan pada skor posttest antara kelas kontrol dan kelas eksperimen pada pembelajaran matematika dengan multimedia interaktif (Muthulakshmi \& Veliappan, 2016). Penelitian lain yang juga mendukung penggunaan multimedia dalam pembelajaran yakni penelitian yang dilakukan oleh Amir et al. (2018), bahwa multimedia interaktif secara signifikan meningkatkan penalaran matematis siswa dalam hal menganalisis data, mengajukan dugaan, memverifikasi, menarik kesimpulan, dan memeriksa validitas argumen. Selain itu respon dan motivasi siswa dalam pembelajaran matematika berbasis multimedia interaktif juga menunjukkan respon yang positif.

Telah dilakukan beberapa penelitian pengembangan media pembelajaran namun belum ada penelitian sebelumnya yang mengembangkan media pembelajaran multimedia interaktif macromedia flash untuk perkuliahan IPA Terpadu.

Pada pembelajaran IPA Terpadu sendiri di tingkat perguruan tinggi belum pernah dilakukan penelitian tentang penggunaan media pembelajaran multimedia interaktif berbantuan macromedia flash. Penelitian sebelumnya hanya pada tingkat SMP yang memperlihatkan adanya peningkatan aktivitas siswa, hal ini menunjukkan bahwa pengembangan media pembelajaran berbasis e-learning pada tema matahari dapat diterima oleh siswa (Mustika et al. 2014).

Berdasarkan penelitian yang telah dilakukan sebelumnya, keterbaruan 
penelitian ini terletak pada pengembangan media pembelajaran berbantuan macromedia flash pada perkuliahan IPA Terpadu. Penelitian ini diharapkan mampu menjawab pertanyaan bagaimana respon dosen dan mahasiswa menggunakan multimedia interaktif di dalam proses pembelajaran IPA Terpadu. Respon dosen dan mahasiswa dianggap penting untuk dianalisis pada penelitian ini, karena mahasiswa dan dosen merupakan pengguna dari media pembelajaran yang dikembangkan. Respon dosen dan mahasiswa sebagai indikator keberhasilan media yang dikembangkan. Bagi dosen media ini diharapkan mampu meminimalisir waktu yang dibutuhkan dosen dalam mengajar, juga meminimalisir miskonsepsi pada materi IPA Terpadu. Bagi mahasiswa, ketertarikan mahasiswa terhadap media merupakan salah satu indikator keberhasilan media yang dikembangkan. Selain itu dengan penggunaan media pembelajaran macromedia flash mampu menyampaikan materi dengan jelas, sehingga mampu memicu motivasi dan antusiasme belajar mahasiswa.

\section{METODE PENELITIAN}

Metode penelitian yang digunakan dalam penelitian ini adalah penelitian kualitatif. Metode penelitian kualitatif dapat diartikan sebagai metode penelitian yang berlandaskan pada filsafah positivism, digunakan untuk meneliti pada populasi atau sampel tertentu. Teknik pengambilan sampel pada umumnya random, pengumpulan data menggunakan instrumen penelitian, analisis data bersifat kuantitatif/ statistik dengan tujuan untuk menguji hipotesis yang telah ditetapkan (Sugiyono, 2017).

Penelitian ini merupakan penelitian kualitatif, dengan fokus penelitian respon dosen dan mahasiswa terhadap penggunaan media pembelajaran multimedia interaktif macromedia flash dalam perkuliahan IPA Terpadu. Adapun sampel penelitian sebanyak 5 orang dosen dan 35 orang mahasiswa. Instrumen penelitian yang digunakan dalam penelitian ini berupa angket respon dosen terhadap penggunaan media pembelajaran multimedia interaktif macromedia flash dan angket respon mahasiswa terhadap penggunaan media pembelajaran multimedia interaktif macromedia flash. Sebelum melakukan penelitian, instrumen penelitian terlebih dahulu diuji validitasnya oleh validator (ahli/pakar). Setelah valid, tahap selanjutnya adalah uji lapangan. Setelah data terkumpul, selanjutnya data dianalisis secara deskriptif.

Riset yang dilakukan dalam penelitian ini meliputi beberapa tahapan yaitu:

1. Mengidentifikasi materi-materi IPA Terpadu yang sesuai menggunakan model pembelajaran konseptual interaktif dan mulitimedia interaktif macromedia flash.

2. Melakukan analisis konsep terhadap materi yang telah diidentifikasi.

3. Mengidentifikasi materi IPA Terpadu yang memungkinkan terjadinya miskonsepsi pada mahasiswa.

4. Merancang skenario pembelajaran dan media pembelajaran multimedia interaktif macromedia flash.

5. Melakukan implementasi pembelajaran pada mahasiswa.

6. Melakukan analisis terhadap data temuan yang berupa tanggapan dosen dan mahasiswa terhadap penggunaan media pembelajaran yang dikembangkan, selanjutnya menarik kesimpulan.

Teknik analisis data terhadap tanggapan mahasiswa terhadap penggunaan media pembelajaran, menggunakan teknik pengumpulan data berupa penyebaran angket dan wawancara. Sedangkan untuk 
teknik analisis data terhadap tanggapan dosen terhadap media pembelajaran multimedia interaktif macromedia flash termasuk kendala-kendala yang dihadapi dosen saat menggunakan media, menggunakan teknik pengumpulan data wawancara, dengan instrumen berupa pedoman wawancara.

Agar memudahkan dalam mendeskripsikan respon dosen dan mahasiswa, dilakukan perhitungan persentasi keidealan respon dosen dan mahasiswa terhadap penggunaan media pembelajaran dengan persamaan:

$$
P=\frac{S}{N} \times 100 \%
$$

Keterangan:

$$
\begin{array}{ll}
\mathrm{P} & =\text { Persentase ideal } \\
\mathrm{S} & =\text { Jumlah komponen hasil penelitian } \\
\mathrm{N} & =\text { Jumlah skor maksimum (modifikasi }
\end{array}
$$
Purwanto, 2008).

\section{HASIL DAN PEMBAHASAN}

\section{Hasil Penelitian}

Hasil penelitian berupa tanggapan dosen dan mahasiswa terhadap penggunaan media pembelajaran multimedia interaktif dengan macromedia flash dapat dilihat

\begin{tabular}{|c|c|c|}
\hline \multirow[b]{2}{*}{ No } & \multicolumn{2}{|c|}{ Respon Dosen } \\
\hline & Indikator Angket & $\begin{array}{l}\text { Persentase } \\
\text { Respon } \\
\text { Positif } \\
\text { Dosen }(\%)\end{array}$ \\
\hline 1 & Kualitas dan tampilan media & 88,00 \\
\hline 2 & Ilustrasi & 84,00 \\
\hline 3 & Materi & 84,00 \\
\hline 4 & Daya tarik & 83,00 \\
\hline & Rata-rata & 84,25 \\
\hline
\end{tabular}
sebagai berikut:

Tabel 1. Persentase Respon Dosen terhadap Penggunaan Media Pembelajaran

Tabel 2. Persentase Respon Mahasiswa terhadap Penggunaan Media Pembelajaran

No Respon Mahasiswa


Dari hasil penelitian diperoleh respon positif baik dari dosen pengampuh dan yang pernah mengampuh mata kuliah IPA Terpadu, maupun dari pihak mahasiswa. Adapun indikator angket respon dosen yaitu kualitas dan tampilan media, ilustrasi, materi, dan daya tarik media.

Sedangkan indikator untuk angket respon penilaian mahasiswa terhadap penggunaan media pembelajaran yaitu kualitas, Bahasa, ilustrasi, kegunaan, dan fleksibilitas.

Hasil penelitian menunjukkan bahwa dari keempat indikator respon dosen terhadap penggunaan media pembelajaran multimedia interaktif dengan macromedia flash memberikan nilai rata-rata respon positif sebesar $84,25 \%$, sedangkan dari kelima indikator respon mahasiswa memberikan nilai rata-rata respon positif sebesar $82,66 \%$.

Data hasil penelitian tersebut sejalan dengan beberapa penelitian yang juga mengembangkan dan menggunakan media pembelajaran, seperti penelitian yang dilakukan oleh Ramadhani \& Andre (2019), yang menunjukkan data respon positif dosen terhadap penggunaan media pembelajaran dengan branching program sebesar 90,83\% dan respon positif mahasiswa sebesar $89,78 \%$.

Selain respon positif dari dosen dan mahasiswa, peneliti juga menemukan beberapa kendala yang menjadi penghambat keterlaksanaan penggunaan media pembelajaran multimedia interaktif dengan macromedia flash ini di lapangan, seperti:

1. Kurangnya kemampuan dosen dalam mengembangkan media pembelajaran multimedia interaktif dengan macromedia flash.

2. Kurangnya ketersediaan multimedia interaktif yang sesuai konten materi perkuliahan.
3. Terbatasnya waktu dosen pengampuh dalam mengembangkan media pembelajaran multimedia interaktif yang serupa dengan penelitian ini.

4. Tuntutan capaian pembelajaran yang ingin dicapai terlalu luas dan kompleks, dan tidak sebanding dengan waktu perkuliahan.

\section{PENUTUP}

Berdasarkan hasil penelitian dapat disimpulkan hasil rerata persentase respon dosen dalam penggunaan media pembelajaran multimedia interaktif dengan macromedia flash menunjukkan respon positif sebesar $84,25 \%$, sedangkan hasil rerata persentase respon mahasiswa dalam penggunaan media pembelajaran multimedia interaktif dengan macromedia flash menunjukkan respon positif sebesar $82,66 \%$.

Adapun rekomendasi yang dapat diberikan terkait dengan penelitian ini, yaitu kepada dosen/ peneliti selanjutnya yang ingin mengembangkan atau menggunakan media pembelajaran ini, sebaiknya melakukan analisis materi dan konten terlebih dahulu sebelum menentukan tema yang akan dibuat.

\section{UCAPAN TERIMAKASIH}

Penulis mengucapkan terima kasih kepada semua pihak yang telah berkontribusi pada penelitian ini, terutama Bapak/ Ibu tim pengampuh mata kuliah IPA Terpadu, juga LP3M Unismuh Makassar yang telah mendanai penelitian ini melalui hibah internal LP3M Universitas Muhammadiyah Makassar.

\section{REFERENSI}

Amir, M. F., Hasanah, F. N., \& Musthofa, H. (2018). Interactive Multimedia Based Mathematics Problem Solving to 
Develop Student s' Reasoning. Int. J. Eng. Technol, 7(2.14), 272-276.

Dewi, S. R., \& Haryanto, H. (2019). Pengembangan multimedia interaktif penjumlahan pada bilangan bulat untuk siswa kelas IV sekolah dasar. Premiere Educandum: Jurnal Pendidikan Dasar dan Pembelajaran, 9(1), 9-22.

Hadijah, S. (2018). Analisis Respon Siswa dan Guru Terhadap Penggunaan Multimedia Interaktif Dalam Proses Pembelajaran Matematika. Numeracy Journal, 5(2). 176-183.

Haeroni, H., Susilawati, S., \& Rahayu, S. (2019). Remediasi Miskonsepsi Peserta Didik Pada Materi Optik Dengan Teknik CRI Modifikasi Melalui Model Learning Cycle 5E. Jurnal Pendidikan Fisika dan Teknologi, 5(1), 91-99.

Hariyati. (2014). Pengaruh Penggunaan Media Pembelajaran terhadap Hasil Belajar Siswa pada Mata Pelajaran IPS Terpadu di SMP Negeri 12 Palu. EJournal Geo-Tadulako UNTAD. Hal. 1-16.

Leow, F. T., \& Neo, M. (2014). Interactive Multimedia Learning: Innovating Classroom Education in A Malaysian University. Turkish Online Journal of Educational TechnologyTOJET, 13(2), 99-110.

Marisda, D.H \& Rahmawati (2018). Model Pembelajaran Konseptual Interaktif dalam Mata Kuliah IPA Terpadu, dalam Prosiding Simposium Fisika Nasional (SFN)-XXXI Inovasi Fisika. Medan, 21-22 September 2018. Physical Society of Indonesia SUMUT.

Muthulakshmi, P., \& Veliappan, A. (2016). Effectiveness of an Interactive Multimedia Learning Package in Developing Attitude towards Mathematics. Journal on School Educational Technology, 11(3), 4046.
Pratiwi, Y. I., Budiharti, R., \& Ekawati, E. Y. (2014). Pengembangan Media Pembelajaran IPA Terpadu Interaktif Dalam Bentuk Moodle Untuk Siswa SMP Pada Tema Matahari Sebagai Sumber Energi Alternatif. Jurnal Pendidikan Fisika, 2(1). 26-30.

Pratiwi, R., Hikmawati, H., \& Gunada, I. W. (2019). Pengaruh Model Pembelajaran Probing Prompting Berbantuan Video Terhadap Hasil Belajar Dan Kemampuan Berpikir Kritis Peserta Didik. Jurnal Pendidikan Fisika dan Teknologi, 5(2), 213-220.

Purwanto. (2008). Metodologi Penelitian Kuantitatif. Yogyakarta: Pustaka Pelajar.

Rahmawati, A. S., \& Dewi, R. P. (2019). Penggunaan Multimedia Interaktif (MMI) Sebagai Media Pembelajaran Dalam Meningkatkan Prestasi Belajar Fisika. Jurnal Pendidikan Fisika dan Teknologi, 5(1), 50-58.

Ramadhani, W., \& Andre, J. (2019). Pengembangan Media Pembelajaran dengan Branching Program Berbasis Komputer. Jurnal Teknologi Informasi dan Pendidikan, 12(1), 1118.

Sari, F. K., Farida, F., \& Syazali, M. (2016). Pengembangan Media Pembelajaran (Modul) berbantuan Geogebra Pokok Bahasan Turunan. Al-Jabar: Jurnal Pendidikan Matematika,7(2), 135152.

Sugiyono. (2017). Metode Penelitian Pendidikan Pendekatan Kuantitatif, Kualitatif, dan $R \& D, \quad$ Edisi.1. Bandung: Alfabeta. 